\title{
INOVAÇÃO TECNOLÓGICA: A PRIVATIZAÇÃO APÓS O USO DAS "MOEDAS PODRES"
}

\section{Jalro Laser Proclanoy}

Engenheiro Mecânico pela EE-UFRGS, Professor

Assistente de Administração Financeira no

PPGA/FCE/UFRGS, Doutorando na FEA/USP, Consultor de Empresas pela JLP Consultoria e Participações S/C Ltda.

\section{Paulo Cesar Delaytl Motta}

Economista pela PUC-RS, Professor Adjunto de

Administração Geral no PPGA/FCE/UFRGS.

* RESUMO: Após uma análise dos modelos econômicos de privatização e dos instrumentos financeiros inovadores, apresentamos os aspectos relevantes das Ações Preferenciais Resgatáveis (APR) brasileiras, como uma forma de obter recursos junto ao mercado de capitais e suas caracteristicas mais importantes. Tendo o exemplo da bem-sucedida nacionalização da subsidiária da Massey Perkins, sugerimos a utilização de APRs na privatização brasileira, como uma maneira de captar recursos de longo prazo para o novo acio- nista controlador e obter melhores preços para as ações a serem vendidas pelo Governo sem ter que esperar um mercado bursátil em alta depois do uso das "moedas podres".

* PalaVRas-ChaVe: Privatização, mercado de capitais, Brasil.

* ABSTRACT: After an analysis of the privatization economic model and the innovative financial instruments, we present the key aspects of the Brazilian Redeemable Preferred Shares as a way of raising funds in the stock market and its most important characteristics. Taking as an example the very successful nationalization of the Massey Perkins subsidiary, in Brazil, we suggest the usage of the Redeemable Preferred Shares in the Brazilian privatization program as a way to raise long term funds for the new majority shareholders and to get a better price for the government's assets without waiting the "right" bull market after the usage of the "moedas podres".

* KEY WORDS: Privatization, capital market, Brazil.

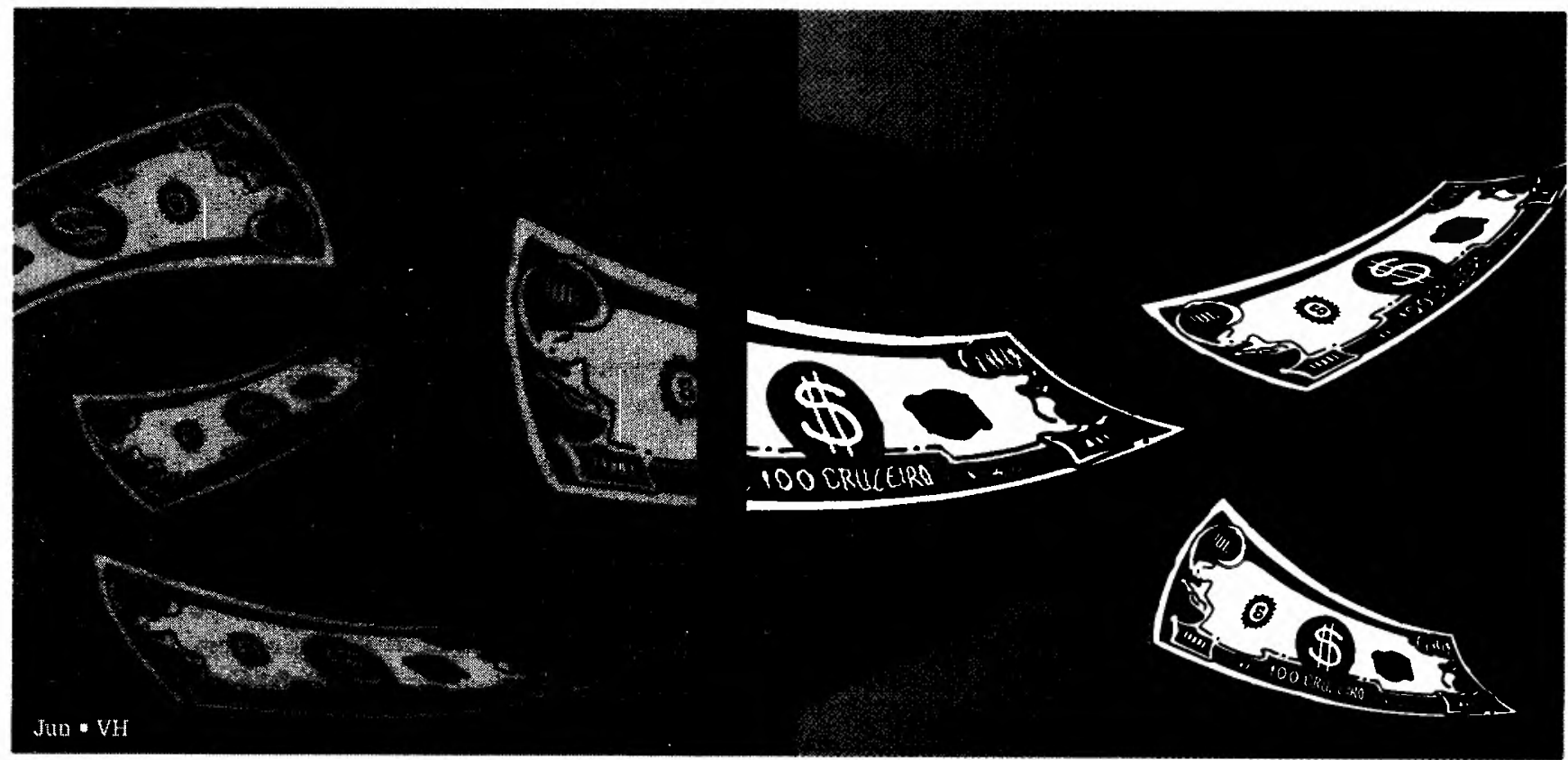




\section{INTRODUÇÃO}

Quando se fala em tecnologia, imediatamente, imaginamos que se está referindo a máquinas, produtos e processos. $O$ conceito de tecnologia, no entanto, não é apenas referido a esses aspectos de produção de bens. Ele inclui, também e principalmente, as formas pelas quais se organizam e administram os processos de produção de bens e serviços, assim como os próprios processos de geração de conhecimentos e de inovação tecnológica. Esta outra face da tecnologia é chamada tecnologia gerencial, sem a qual as inovações não conseguiriam chegar como produto ao consumidor.

As tecnologias gerenciais, no âmbito da administração financeira, revestem-se de grande importância e significado no contexto de países subdesenvolvidos como o Brasil. As altas taxas de inflação, os custos elevados do dinheiro, a ausência de mecanismos de financiamento de médio e longo prazos, a fragilidade das bolsas de valores e uma recessão prolonga$\mathrm{da}$, entre muitos outros fatores, fazem com que seja não apenas necessário, mas absolutamente vital para a sobre-

Apesar das caracteristicas da economia brasileira, as primeiras privatizações realizadas obtiveram sucesso, devido à qualidade das empresas privatizadas e à existência de moedas podres. vivência das empresas brasileiras, que haja um movimento de constante inovação nas tecnologias gerenciais e nos instrumentos de administração financeira à disposição tanto do setor privado quanto do setor público.

Um mercado secundário de ações subdesenvolvido e constantemente em baixa (valor de mercado das ações inferior ao seu valor patrimonial), as poupanças escassas, investidores estrangeiros que ainda não vêem credibilidade suficiente para aplicar os seus recursos no país (devido à percepção de alta inflação e do risco político), e a não disponibilidade de instrumentos financeiros de longo prazo para financiar a troca de controladores das empresas públicas para a iniciativa privada fazem com que a tarefa privatizadora proposta pelo Governo brasileiro, a partir da posse do Presidente Fernando Collor de Mello em março de 1990, seja ainda mais árdua que a de outros países que tenham a mesma intenção.

Apesar dessas características da economia brasileira, as primeiras privatizações realizadas obtiveram sucesso, devido à qualidade das empresas privatizadas e à existência de moedas podres.

As moedas podres, que são títulos de dívida governamental vendidos no mercado secundário com altos deságios, têm desempenhado o importante papel de instrumento financeiro de longo prazo na efetiva realização das transferências de controle acionário das empresas privatizadas.

Entretanto, questiona-se o que acontecerá quando diminuir o interesse na aquisição de empresas privatizáveis e, principalmente, quando terminar o estoque de moedas podres.

Essas questões encaminham para a constatação de que a inovação tecnológica na área financeira torna-se elemento indispensável para propor soluções necessárias e adequadas à realização do programa de privatização. As Ações Preferenciais Resgatáveis (APRs) aparecem como o instrumento inovador correto para a realização desse programa. 
1. DE FRAJA, Giovanni. "Efficiency and Privatization in Imperfectly Competitive Industries". The Journal of Industrial Economi, Mar. 1991, pp. 311-21.

2. CÁRNEDAS, Emilio J. "Argentina: privatization law in place". International Financial Law Review, Nov. 1989, pp. 30-1.

3. LIPTON, David \& SACHS Jeffrey. "Privatization in Eastern Europe: the case of Poland". Brookings Papers on Economic Activity, volume 2, 1990 , pp.293-333.
Encontramos o exemplo da utilização desse instrumento ao examinarmos a experiência da nacionalização da Massey Perkins S.A. pela Companhia Iochpe de Participações, em 1986, onde as APRs foram colocadas junto ao público investidor para compor o quadro das fontes de recursos do projeto. Naquele momento, os riscos econômicos e financeiros percebidos pelos diversos possíveis investidores, aliados ao momento de bolsa em baixa, foram dificuldades muito semelhantes às que são enfrentadas agora pelo Governo, na venda das estatais.

Essas dificuldades, entretanto, podem ser transponíveis com a utilização das Ações Preferenciais Resgatáveis como o instrumento inovadoramente correto para a realização do programa de privatização do Governo brasileiro.

Primeiramente, examinaremos os pontos essenciais da privatização; a seguir, a criação de instrumentos financeiros inovadores; as ações preferenciais resgatáveis (APRs) como forma inovadora de captação de recursos e suas características. Logo após, apresentaremos o estudo do caso da nacionalização da Massey Perkins S.A.

\section{PRIVATIZAÇÃO}

A privatização é a atitude, por parte de um Governo, de transferir o poder de decisão de empresas de sua propriedade para investidores privados.

Durante os últimos anos, encontramos projetos extensivos de privatização no mundo desenvolvido (Inglaterra, França e Itália), no Leste Europeu (Polônia, Hungria, Tchecoslováquia) e nas economias da América Latina (Chile, Argentina, México, Venezuela). O Brasil, a partir da posse do Presidente Fernando Collor, resolveu realizar um intenso esforço para diminuir a presença do Estado na economia.

De Fraja ${ }^{1}$ resume os argumentos para a privatização:

a. na redução da ineficiência produtiva, o lucro é mais eficiente do que o monitoramento da gestão pública, isto é, a empresa privada é mais eficiente do que a empresa pública;

b. uma empresa mais eficiente aumenta a eficiência setorial.

Segundo o autor, a maior eficiência setorial não é uma conseqüência obrigatória da privatização e pode ser obtida quando uma empresa pública oligopolística trabalha com custos subsidiados, forçando seus concorrentes a buscar a eficiência empresarial, cujos mecanismos desapareceriam no momento da troca de controle. Da mesma forma, em setores altamente lucrativos e cujas barreiras de entrada para novos competidores sejam poucas, a privatização será benéfica para a economia.

Conforme Cárdenas², o grande setor público da economia argentina era economicamente inviável, porque ineficiente, sendo o consumidor o perdedor, não somente pelos serviços de má qualidade, mas também pelos altos custos, equipamentos primitivos e, principalmente, pela corrupção existente. O programa de privatização está sendo realizado com o objetivo de que, ao concluí-lo, a economia tenha mudado totalmente as suas características pela eliminação ou o desmantelamento dos privilégios, das restrições e dos monopólios.

$\mathrm{Na}$ Polônia, assim como em todo o Leste Europeu, segundo Lipton e Sachs ${ }^{3}$, além da passagem das empresas para a iniciativa privada, está sendo necessária a criação de um eficiente mercado de capitais, 
que tem a função de monitorar a gestão das empresas privatizadas e possibilitar a diversificação dos riscos da propriedade. Neste caso, $o$ grande desafio político é a criação de mecanismos que possibilitem a existência da propriedade privada e que possam ganhar o amplo apoio da sociedade em geral.

Ainda segundo Lipton e Sachs, a grande questão que se coloca na privatização é a velocidade da sua realização. Os que advogam pela privatização rápida, através da distribuição de ações entre os diversos agentes, ponderam que os benefícios da propriedade privada são muito maiores que as eventuais perdas geradas por proprietários equivocados, ou que não tenham as qualificações necessárias para a gestão dessas empresas, e que esses problemas serão solucionados pelos mecanismos de take-over, fusões e aquisições, características do mercado de capitais.

Outros autores, como Kornai ${ }^{4}$, defendem que a privatização deve ser feita com o objetivo de estabelecer a efetiva propriedade e o controle das empresas, ao invés de simplesmente transferir nominalmente as ações para a iniciativa privada. Por outro lado, não pode ser esquecida a velocidade necessária, pois os processos de privatização correm o risco de parar em função de divergências políticas, no momento em que os diversos agentes econômicos envolvidos passarem a reclamar dos possíveis prejuízos resultantes.

Um exemplo significativo dessa circunstância é o que aconteceu no Brasil com a privatização da Usiminas, onde as pressões políticas regionais utilizaram o poder judiciário para embargar o processo, retardando-o e criando situações muito delicadas para todos os participantes. Cabe lembrar, que as privatizações realizadas até o momento (Usiminas, Celma, Mafersa, Cosinor, Sociedade de Navegação Bacia do Prata, Aços Finos Piratini, Indag, Petroflex e Copesul), foram coroadas de sucesso com a venda total da participação do Estado para grupos privados ou fundos de pensão.

Lipton e Sachs ${ }^{5}$, adicionalmente, chamam a atenção para o fato de que a venda rápida das ações só se dará se o índice $\mathrm{P} / \mathrm{L}$ (preço/lucro) das ações for muito baixo, o que resultaria na transferência dos ativos a valores irrelevantes, ou caso o governo financie os compradores, ou ainda caso a venda seja feita principalmente para estrangeiros, que são detentores de poupanças capazes de realizar esses investimentos.

Luders, Hanson e Yotopoulos ${ }^{6}$, individualmente, estudaram a privatização ocorrida no Chile durante os anos de 1975 a 1978, no pacote de primeiras medidas do Governo Pinochet. As empresas privatizadas estavam subcapitalizadas e muito endividadas, o que ocasionou a renacionalização de muitas delas durante a crise financeira dos anos 1982 e 1983. Isto significa que empresas endividadas, proprietários fracos e instrumentos inadequados podem gerar o retorno das privatizações para o Governo, caso ocorra um processo recessivo.

Segundo Modiano ${ }^{7}$, presidente do Banco Nacional de Desenvolvimento Econômico e Social (BNDES), o processo de desestatização é o instrumento fundamental na redefinição do papel do Estado, onde a ação do "Estado Empresário" deve ser mínima para que as funções

4. KORNAI apud LIPTON, David \& SACHS, Jeffrey. Op. cit.

5. LIPTON, David \& SACHS, Jeffrey. Op. cit.

6. LUDERS, HANSON \& YOTOPOULOS apUd LIPTON, David \& SACHS, Jeffrey. Op. cit.

7. SEMINÁRIO DE AVALIAÇÃO DE EMPRESAS E PRIVATIZA. ÇÃO. Revista da ADEVAL, São Paulo, jan. 1991, pp.23-37. 
8. GOODMAN, John B. \& LOVEMAN, Gary W. "Does Privatization Serve the Public Interest?" Harvard Business Review, NovDec. 1991, pp.26-38.

9. EXECUTIVOS Financeiros. Rio de Janeiro, ano IV, (22):202, 1991.

10. KANE, Edward J. "Accelerating Inflation, Technological In novation, and the Decreasing Effectiveness of Banking Regulation". Journal of Finance, Mayi. 1981, pp.355-67.

11. MILLER, M. H. "Financial Innovation: the Last Twenty Years and the Next". Journal of financial Quantitative Analysis, Dec. 1986, pp.459-71.

12. KANE, Edward J. "Technological and Regulatory forces in the Developing Fusiion of Financial Services Competiton". Journal of Finance, Jul. 1984 pp.759-72.

13. SILBER, William L. "The Process of Financial Innovation". American Economic Review, May. 1983, pp.88-95. nas áreas sociais sejam adequadamente executadas, devendo ficar garantido ao setor privado o desejo e a obrigação de realizar os investimentos empresariais.

Goodman e Loveman ${ }^{8}$ enfatizam que a real privatização irá acontecer quando da troca efetiva da gestão das empresas ou, no mínimo, da postura gerencial da mesma frente a sua nova realidade. Novos incentivos deverão ser dados aos gestores, objetivando a maximização da riqueza dos acionistas, ou seja, maiores lucros com menores riscos operacionais e financeiros.

No Brasil, é permitido o uso de Títulos da Dívida Agrária (TDAs), cruzados bloqueados, debêntures de estatais, e outros títulos como moeda para pagamento na compra de empresas a serem privatizadas $^{9}$. Essas moedas são consideradas moedas podres, por terem sido vendidas compulsoriamente às instituições financeiras e aos fundos de pensão pelo Governo Federal, em diversos momentos de nossa história recente. O preço de mercado dessas moedas é bastante inferior aos seus valores de face, pois dificilmente serão resgatadas e, conseqüentemente, não existem investidores espontâneos.

Como elementos dificultadores do processo de privatização, temos as poupanças internas, que são pequenas, e a acentuada percepção dos agentes econômicos sobre os riscos envolvidos. A bolsa de valores, elemento-chave na definição dos valores das ações, apresenta índices $\mathrm{P} / \mathrm{L}$ muito baixos. O financiamento para os compradores pode gerar, no futuro, um repasse desses custos e riscos para as próprias empresas, resultando na instabilidade do processo.

\section{A CRIAÇÃO DE INSTRUMENTOS FINANCEIROS INOVADORES}

A criação de instrumentos financeiros inovadores está intimamente ligada ao questionamento de por que eles aparecem no mercado a cada momento, qual objetivo de sua criação e quais são aqueles que são válidos.

$\mathrm{Kane}^{10}$ apresenta uma diferença clara entre invenção e inovação no meio financeiro. Invenção é o ato de encontrar novas formas de fazer coisas utilizáveis ou lucrativas, ou, ainda, maneiras baratas e eficientes de fazê-las. Inovação é o ato de pôr em prática uma invenção. Esta é uma descoberta científica ou técnica; inovação é a implementação de uma decisão administrativa. Ele afirma ainda que antes de uma invenção poder ser utilizada comercialmente, as oportunidades que se apresentam devem oferecer suficientes lucros, após impostos, de tal forma que ultrapassem o custo de movimentar a inércia institucional e a resistência dos empregados e gestores em mudar seus hábitos.

Miller ${ }^{11}$ argumenta que a regulamentação e os impostos foram os maiores responsáveis pela inovação nos instrumentos financeiros existentes durante os últimos 20 anos. $O$ autor descreve as inovações financeiras como "aperfeiçoamentos imprevisíveis", resultantes das modificações inesperadas da regulação e das regras dos impostos diversos.

Ao discutir a questão da regulação, $\mathrm{Kane}^{12}$ diz existir uma "dialética regulamentadora", isto é, um processo cíclico no qual forças opostas em torno de uma nova regulamentação se adaptam continuamente.

Silber ${ }^{13}$ caracteriza os instrumentos financeiros inovadores e os processos criativos, geralmente, como uma tentativa por parte das empresas para diminuir as restrições financeiras que lhes são impostas. As empresas maximizam a utilidade quando sujeitas a restrições, sendo 
que algumas das restrições impostas pela regulamentação governamental acarretam uma contrapartida pelo mercado, ou pela própria empresa. A atividade inovadora responde, então, aos impulsos econômicos, o que aumenta o custo de se amoldar às restrições. Por sua vez, o aumento do custo conseqüente estimula a atividade inovadora com o objetivo de diminuir a restrição e reduzir o custo de adesão.

Van Horne ${ }^{14}$ argumenta que, para um novo instrumento ou processo financeiro ser realmente inovador, ele tem que possibilitar ao mercado uma operação mais eficiente, ou fazê-la mais completa. Se os mercados financeiros fossem perfeitos e completos, não haveria a possibilidade de inovação. A maior eficiência pode ser obtida com a redução dos custos de transação, ou pela redução do diferencial dos impostos. O mercado financeiro pode ser mais completo se desenhar um instrumento financeiro inovador, cujo retorno após impostos não possa ser obtido por nenhuma combinação dos instrumentos já existentes.

Finnerty ${ }^{15}$ desenvolveu uma estrutura analítica que indica as três principais fontes de aumento do valor através da inovação financeira para as ações:

Na privatização da Usiminas, as pressões políticas regionais utilizaram o poder judiciário para embargar o processo, retardando-o e criando situações muito delicadas para todos os participantes.

- artifícios que realocam ou reduzem o risco e, por conseqüência, o retorno esperado;

- artifícios que criem uma arbitragem fiscal entre o emissor e o investidor, repassando o custo para o Estado.

Finnerty ${ }^{16}$ sugere que os fatores responsáveis pela inovação dos instrumentos financeiros podem ser classificados em dez categorias:

1. assimetria de impostos, que pode ser explorada com o objetivo de proporcionar a redução dos mesmos para uma ou ambas as partes envolvidas na transação, sem criar passivos fiscais para nenhuma delas;

2. custos de transação;

3. custos de agência;

4. oportunidade de reduzir ou de realocar o risco para um parceiro menos avesso ao risco, ou disposto a operar com um menor retorno para o mesmo risco;

5. oportunidades de aumentar a liquidez de algum ativo;

6. modificação de um regulamento ou da legislação;

7. nivel e volatilidade das taxas de juros;

8. trabalho acadêmico que resulte em um avanço na teoria, ou que permita um melhor entendimento da relação risco/retorno dos títulos existentes;

9. benefícios contábeis, que resultem na maior riqueza dos acionistas;

10. avanços tecnológicos.

Ao discutir a questão da inovação nas ações, Shapiro ${ }^{17}$ afirma que esse procedimento tem por objetivo desenvolver mecanismos que possibilitem o financiamento a valores presentes líquidos positivos.

Weston e Copeland ${ }^{18}$ ao investigarem os motivos de uma empresa ter diversos tipos de títulos, afirmam que os investidores apresentam

14. VAN HORNE, James C. "Of Financial Innovations and Excesses". Journal of Finance, Jul. 1985, pp.612-31.

15. FINNERTY, John D. "An Analytical Framework for Evaluating Securities Innovations". Journal of Corporate Finance, Winter, 1987, pp.3-18.

16. FINNERTY, John D. "Financial Engineering in Corporate Finance: an overview". Financial Management, Winter 1988, pp.14-33.

17. SHAPIRO, A.C. "Guidelines for Long-Term Corporate Financing Strategy". Midland Corporate Finance Journal, Winter 1986, pp.6-19.

18. WESTON, J. Fred \& COPELAND, Thomas E. Managerial Finance. $8^{2}$ edição. Hinsdale, EUA, The Dryden Press, 1986. 
19. BRASIL. Lei $n^{0} 6.404$ - Dispõe sobre as Sociedades por Ações, 7 de dezembro de 1976.

20. REVISTA da Comissão de Valores Mobiliários. Rio de Janeiro, set./dez. 1983. Parecer sobre Resgate de Ações - atuaÇão reguladora da CVM 1(3):19-33

21. ARCHER, Stephen $\mathrm{H}$; $\mathrm{CHOA}$ TE. G. Marc \& RACETTE, George. Financial Management - An Introduction. New York, John Wiley and Sons, 1979.

22. SAMUELS, J. M. \& WILKES, F. M. Management of Company Finance. $2^{\mathrm{a}}$ edição. Londres, Thomas Nelson and Sons, 1975.

23. BIERMAN Jr., Harold \& SMIDT, Seymour. Financial Management for Decision Making. New York, Mcmillan, 1986.

24. LEVY, Haim \& SARNAT, Marshall. Principles of Financial Management. Englewood Cliffs, New Jersey, Prentice-Hall, 1988.

25. Conforme a Seção II, Capítulo VII da Lei no 6.404/76.

26. Conforme Artigo 4, Parágrafo Único da Lei $n^{\circ} 6.404 / 76$.

27. Conforme Seção III, Capítulo VII da Lei $n^{0} 6.404 / 76$. diferentes preferências na relação risco/retorno. Dessa forma, quanto maior for a diversificação das possibilidades oferecidas aos investidores, menor pode ser o custo do capital da empresa, maximizando, assim, a riqueza dos seus acionistas.

\section{AS AÇÕES PREFERENCIAIS RESGATÁVEIS COMO FORMA INOVADORA DE CAPTAÇÃO DE RECURSOS}

Em princípio, toda e qualquer ação pode ser resgatada a qualquer momento, bastando para isto uma decisão da assembléia. Embora legalmente permitido o resgate das ordinárias, deve-se observar o cumprimento ao que foi estabelecido pela regra de emissão de ações de no máximo dois terços de preferenciais para um terço de ordinárias. $O$ resgate das ordinárias não é possível, pois sem estas não existe companhia aberta.

Outra possibilidade, citada nos artigos 19 e 44 da Lei $\mathrm{n}^{\circ}$ $6.404 / 769^{19}$, é a previsão do resgate já no nascimento de determinada classe de ação preferencial; esse tipo de ação será, a partir deste momento, considerada como "Ação Resgatável". Deve ser ressaltado, no entanto, que nas companhias abertas isto só se verifica em relação às ações preferenciais, pois, conforme estabelecem os artigos 15 e 16 da referida Lei, não é permitida mais do que uma classe de ações ordinárias, uma vez que o uso dessa prerrogativa resultaria na extinção dessas empresas.

Conforme parecer da Comissão de Valores Mobiliários (CVM) ${ }^{20}$, é possível designar de resgate compulsório aquele previsto desde a emissão da ação e pelo qual a companhia se obriga a resgatar uma determinada classe com esta finalidade, desde que tenha fundos para tanto.

A literatura financeira americana trata a ação resgatável como uma possibilidade, uma opção da empresa emissora, ou seja, uma variação da ação preferencial. Note-se que isto se deve, em boa parte, ao caráter diferenciado das ações preferenciais americanas em relação às brasileiras. Aqui têm-se, na quase totalidade dos casos, ações preferenciais que partilham o lucro, dividendo pago aos acionistas, em condições iguais às das ações ordinárias. Nos Estados Unidos, conforme explicam Archer, Choate e Racette ${ }^{21}$, as ações preferenciais recebem dividendos fixos e diferentes das ordinárias.

A literatura inglesa, conforme Samuels e Wilkes22, aponta a existência do termo redeemable preference shares para a designação de ações resgatáveis. Constata-se ainda a existência de uma definição de "híbrido" para as ações preferenciais resgatáveis, como apresentam Bierman e Smidt ${ }^{23}$ e Levy e Sarnat ${ }^{24}$. Esses autores sustentam que tal tipo de ação não é, na realidade, uma ação, pois comporta-se como dívida, mas também não é uma dívida, pois tem obrigações como capital.

A experiência brasileira com ações resgatáveis é muito pequena. A ocorrência total desse tipo de operação é de onze casos, sendo nove emissões públicas ${ }^{25}$ em companhias abertas ${ }^{26}$ (Standard Elétrica, Perdigão Alimentos, Perdigão Agroindustrial, Perdigão Comércio e Indústria, Polipropileno, Nitrocarbono, Hering Nordeste, Massey Perkins e CPC - Cia. Petroquímica Camaçari) e duas emissões privadas $^{27}$ em sociedade anônima fechada (Petroquímica Triunfo S.A. e CPM Informática S.A.). É possível que haja outras emissões privadas, pois o acesso a essas informações é difícil, tendo em vista a não obrigatoriedade da divulgação das informações no caso de sociedades anônimas fechadas. 
Das referidas experiências, encontramos sete no ano de 1982, duas em 1984 e uma em 1989. Nota-se que as operações realizadas em 1982 eram conseqüência natural do momento de baixa nas bolsas brasileiras. Mesmo assim, verifica-se que, destas, três (Polipropileno, Nitrocarbono e Hering Nordeste) objetivavam a utilização dos incentivos fiscais para investimentos em empresas localizadas na região da Superintendência de Desenvolvimento do Nordeste (SUDENE), conforme o Decreto-lei no 1.841, de 29/12/8028.

\section{CARACTERÍSTICAS DAS AÇÕES PREFERENCIAIS RESGATÁVEIS}

O equilibrio entre os captadores e os aplicadores de recursos possibilita à empresa encontrar a fonte adequada de financiamento. $O$ instrumento de captação será tanto melhor, quanto maior público investidor conseguir atrair, entendendo-se que, quanto maior for a massa de recursos disponíveis para adquirir esse instrumento, maior será o seu "sucesso". Esse "sucesso" será a capacitação dos recursos dentro

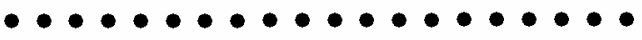

$$
\begin{gathered}
\text { A maior eficiência } \\
\text { pode ser obtida com a redução } \\
\text { dos custos de transação, } \\
\text { ou pela redução } \\
\text { do diferencial dos } \\
\text { impostos. }
\end{gathered}
$$

das melhores condições de mercado, naquele momento, a um volume, custo, risco e prazo mais adequados para a empresa captadora. Essa situação mostra claramente que o estudo individualizado das principais características da APR como um instrumento de captação de recursos é um ponto fundamental para a aplicação do mesmo.

\section{Preço de emissão}

$\mathrm{O}$ preço de emissão de uma APR deve ser regido pela regra geral constante do artigo 170, Parágrafo $1^{\circ}$, da Lei $n^{\circ} 6.404 / 76$, que estabelece que este deve ser fixado, tendo em vista a cotação das ações no mercado, o valor do patrimônio líquido e as perspectivas de rentabilidade da companhia, sem diluição injustificada da participação dos antigos acionistas, ainda que tenham direito de preferência para subscrevê-las. A ação resgatável tem por conceito global um valor de emissão pago no momento da subscrição e um valor de resgate, determinado hoje, a ser pago numa data futura. Será adequado qualquer um, definido como preço de subscrição, desde que atenda às exigências legais.

\section{Valor de resgate}

É o valor pelo qual será resgatada a APR, no momento marcado para tal. Esse valor deve ser claramente expresso e deve guardar correlação com o preço de emissão. Embora as formas descritivas para a determinação do valor de resgate possam ser claras, a preferência por uma determinada fórmula faz com que este seja inequívoco. A fórmula básica utilizada estabelece que o valor de resgate será o valor futuro da diferença entre o valor de subscrição e os eventuais dividendos pagos durante o período, todos corrigidos monetariamente e considerando-se um valor de remuneração adicional. Quando se considera o valor de resgate unitário, deve-se ajustar as bonificações dadas durante $o$ período.

28. BRASIL. Decreto-Lei no 1.841 - Dispõe sobre beneficios fiscais a investimentos de interesse econômico-social, 29 de dezembro de 1980 . 
Fundos para o resgate

A legislação societária, artigos 44 , Parágrafo $1^{2}$, e 200 da Lei $6.404 / 76$, estabelece que os fundos disponíveis para resgate serão originados nas reservas e lucros da companhia, podendo existir uma reserva de destinação explícita para o resgate de ações, se for fixada no estatuto social da empresa, ou que as demais reservas poderão ser utilizadas com o mesmo fim, exceção feita para a Reserva Legal. A existência de fundos para resgate na emissão de APRs aumenta a garantia de recompra para o acionista, pois os fundos para tal já estão reservados.

\section{Forma de resgate}

O resgate das APRs é compulsório para o acionista detentor, exceção feita quando existe a prerrogativa de conversão em outras ações. Caso tenha fundos, na data do resgate, a empresa compra e o acionista é obrigado a vender para resgatar as suas ações.

\section{Dividendos}

Os dividendos das APRs podem apresentar as mesmas condições daqueles das demais ações da companhia, que devem ser estabelecidas juntamente com as demais características dessas ações, quando da criação dessa classe, devendo constar do estatuto social da empresa.

\section{Conversibilidade em outra classe de ações}

A conversibilidade em ações comuns, ordinárias e/ou preferenciais, é uma possibilidade que deve estar claramente definida no estatuto social da empresa, em termos de tipo, forma, classe, período, quantidade, ou, ainda, através de uma fórmula. As ações resgatáveis podem ou não ter a prerrogativa de conversão em outra classe de ações. Essa opção deve estar explícita antes da subscrição por parte dos novos acionistas. A ação resultante da conversão de uma resgatável terá características diversas da original e estas devem ser definidas antes mesmo da subscrição da resgatável. A opção de conversão de resgatáveis em outra classe de ações é única e exclusiva do acionista detentor das mesmas, salvo determinados critérios que coloquem a compulsoriedade da conversão, devendo ser evitada a conversão que possa gerar prejuízo aos demais acionistas da companhia.

\section{Garantias}

As APRs são ações e apresentam todas as garantias e direitos constantes do estatuto social da companhia e da Lei, ou seja, são prioritárias somente em relação às ações ordinárias em caso de liquidação da companhia. Podem haver casos em que a garantia seja reforçada através de um elemento externo no momento do futuro resgate, como garantia adicional, ou de covenants no estatuto social. Essa garantia se faz necessária sempre que o risco da empresa emitente das ações não for suficiente para atrair os investidores. A percepção de alto risco pode ser detectada pelo eventual investidor através do conhecimento da companhia, para empresas já abertas, ou por seu desconhecimento, no caso de empresas que estão abrindo o seu capital através desse instrumento. 


\section{O CASO MASSEY}

Em junho de 1984, um grupo financeiro nacional realizou o "Projeto Massey", com o objetivo de nacionalizar e fortalecer a Massey Fergusson Perkins S.A., empresa que fabrica, basicamente, tratores, colheitadeiras e motores.

Esse projeto envolvia a capitalização adicional de US $\$ 62,5$ milhões aos US $\$ 20$ milhões já existentes. Os fundos adicionais seriam obtidos através de uma capitalização imediata pelo grupo financeiro interveniente de US\$7 milhões, perdão de dívidas e créditos no valor de US\$4,5 milhões e capitalização de outros US $\$ 18,5$, totalizando US $\$ 23 \mathrm{mi}$ lhões pela Massey Fergusson Limited (Canadá), e a transformação de passivos financeiros com instituições nacionais e internacionais no valor total de US\$19 $\mathrm{mi}$ lhões. Para a obtenção do restante, US\$13,5 milhões, realizou-se um lançamento de ações junto ao

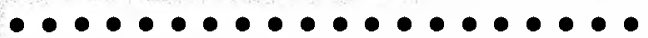

A solução de conversão de dívidas em capital foi a primeira operação de conversão de dívidas realizada no país e previa a liquidez

dos investimentos em um momento futuro. público investidor.

Os passivos financeiros internacionais eram resultantes de empréstimos feitos com a garantia da matriz canadense. Dentro da reorganização da empresa a nível mundial, existia um compromisso de não ajudar as unidades em países que não tivessem participado do reescalonamento total, como o Brasil. Na medida em que os banqueiros externos não queriam participar do capital social da empresa por desejarem manter as suas posiçōes de fornecedores de recursos, houve necessidade de buscar uma inovação utilizando-se um novo instrumento de capitalização. A solução de conversão dessas dívidas em capital foi a primeira operação de conversão de dívidas realizada no país e previa a liquidez dos investimentos em um momento futuro.

A participação dos investidores do mercado de capitais era muito importante, à medida que garantia uma fonte de recursos futuros para a empresa e, ao mesmo tempo, a liquidez para todos os investidores.

A empresa não apresentava prejuizos fiscais relevantes e o benefício fiscal das dívidas - caso fossem utilizadas debêntures conversíveis como instrumento de captação - foi desprezado pelos gestores, pois esse procedimento acarretaria um lucro final menor no balanço de resultados da empresa e, conseqüentemente, mais dúvidas sobre a efetiva recuperação do empreendimento, ocasionando maiores dificuldades para a possível conversão das resgatáveis em ações normais.

Naquele momento, a bolsa de valores apresentava-se em baixa, o que ocasionaria a venda de ações da empresa por valores irrisórios e geraria perdas para os antigos e novos controladores. Também, e principalmente, era muito grande 
a percepção de risco por parte dos diversos agentes investidores.

As ações preferenciais resgatáveis foram a solução. Emitidas em um montante total de US\$18 milhões, tinham o objetivo específico de ser uma via de acesso para os novos acionistas - que temiam pelo futuro da empresa no momento da sua nacionalização - e possibilitar a participação dos banqueiros internacionais. A empresa pagava aos banqueiros da operação de colocação pública de ações uma comissão adicional de $5 \%$ em relação aos $0,5 \%$ originais, caso o acionista, no momento da subscrição, efetuasse a conversão de resgatável para preferencial $A$. O subscritor também recebia um bônus de $50 \%$ caso convertesse as suas ações nos primeiros 60 dias. $O$ incentivo fiscal era desprezivel, já que o seu valor era de apenas $10 \%$.

Em 31/12/84, poucos meses após a sua emissão, 18.443.259.000 e 4.814.281.000 das ações resgatáveis E e F, respectivamente, foram convertidas em preferenciais A. Até $31 / 12 / 85$ tinham sido convertidas mais $1.075 .665 .000 \mathrm{e}$ 42.905.000, respectivamente, das classes $E$ e F para a classe $A$. A totalidade da classe $E$ foi convertida até $31 / 12 / 86$ e mais 50.954 .000 da classe $F$, sendo que o restante foi resgatado por oferta pública em bolsa de valores.

A Parisa Participações e o BNDES, solidariamente, ofereceram garantia de recompra das ações se, no momento do resgate, a empresa não tivesse fundos suficientes para fazê-lo, sem reduzir o capital social. $O$ valor de resgate contemplava correção monetária e juros de $12 \%$ ao ano, conforme a seguinte fórmula de resgate:

$$
V R=\frac{V S \times 1,12^{t} \times d-\sum_{0}^{m}\left(D m \times 1,12^{t m} \times d m\right)}{1+B}
$$

Onde:

$\mathrm{VR}=$ valor unitário de resgate;

VS = valor de emissão;

t $=$ tempo decorrido entre a data de emissão e a data do resgate, expresso em anos, considerando o ano calendário, devendo ser observadas as frações de ano, até a quinta casa decimal;

$\mathrm{d}=$ relação entre o valor das ORTNs na data do resgate e na data de emissão, até a quinta casa decimal;

$\mathrm{Dm}=$ valor dos dividendos distribuídos, sendo denominados os primeiros de D1, os segundos de D2 e assim por diante até os últimos, antes do resgate, denominados Dm;

$\mathrm{tm}=$ tempo decorrido entre a data da efetiva distribuição de cada um dos dividendos e a do resgate, expresso em anos, levando em conta o ano calendário, devendo ser 
consideradas as frações de ano até a quinta casa decimal; $\mathrm{dm}=$ relação entre o valor das ORTNs na data do resgate $e$ na data da efetiva distribuição de dividendos, até a quinta casa decimal;

B = fração decimal que expressa as bonificações, ou desdobramentos de ações ocorridas.

A garantia adicional oferecida pelo novo controlador e pelo BNDES objetivava reduzir a percepção de risco dos investidores e o fato de as ações preferenciais serem resgatáveis garantia, no mínimo, uma rentabilidade positiva para os investidores, eliminando, assim, os riscos inerentes ao mercado de capitais. Caso o mercado reagisse positivamente, $o$ investidor poderia fazer a conversão das suas ações em ações preferenciais normais e realizar ganhos adicionais, como aconteceu.

A emissão de ações correspondeu a um acréscimo de $34,2 \%$ sobre o capital social existente e $27,7 \%$ sobre o número de ações anteriormente emitidas, demonstrando que os volumes foram bastante expressivos para qualquer operação de mercado $e$, ainda mais, para as condições vigentes naquele momento.

Nesta operação de nacionalização da Massey Perkins S.A., hoje Maxion S.A., as ações preferenciais resgatáveis foram utilizadas com maestria. $O$ objetivo era captar recursos não onerosos num mercado em baixa e com grandes dúvidas sobre o futuro do empreendimento. $O$ resultado foi plenamente alcançado, visto que a grande maioria das ações foram convertidas em ações normais a valores bastante próximos do valor patrimonial; o menor foi $66 \%$ deste valor, quando era alto o risco e muito baixa a relação preços de bolsa por valor patrimonial das ações, habitual do mercado brasileiro.

Outro ponto muito importante nesta operação, é o fato de o controlador não ter sido pressionado por nenhum passivo financeiro, seja para si ou para a própria Massey, não colocando em risco a eventual derrocada da empresa em uma possível recessão econômica futura.

\section{CONCLUSÕES}

Para que o processo de desestatização da economia brasileira tenha sucesso, sem ser necessário que o Governo espere o momento adequado para realizá-lo, devem ser criados instrumentos inovadores no mercado de capitais brasileiro que diminuam, ou até anulem, os riscos da nossa economia. As Ações Preferenciais Resgatáveis podem ser uma solução adequada e necessária. $O$ caso de nacionalização da Massey Perkins S.A. é a comprovação disto.

No momento em que se dá a troca do controle acionário e, muito possivelmente, da gestão de uma empresa, verificamos que se modifica a percepção de risco pelos diversos agentes, stakeholders, principalmente nas áreas de crédito e de investimentos em ações. 
A garantia de recompra no prazo final deverá ser dada pelo novo grupo comprador, embora possa contar com a colaboração do BNDES. Assim, ficam configurados um instrumento de captação de recursos de longo prazo e a troca efetiva do risco creditício governamental pelo do grupo empresarial privado.

Ao privatizar uma empresa, o Governo tem o interesse de obter o maior valor possivel pela venda desse ativo. $O$ comprador, por sua vez, visa a otimizar o negócio ao pagar um preço baixo. No momento em que um terceiro agente é convidado para participar e onde lhe é garantida a devolução do investidor com um retorno mínimo por um certo período, ou a possibilidade de conversão em ações comuns, quando aumentar sua rentabilidade, temos a real chance de obter um preço maior para o Governo, sem

A existência de investidores compulsórios para o produto ação representa uma demanda real e uma ajuda efetiva no esforço de privatização. que o novo grupo controlador pague por isto.

É óbvio que o adquirente não se irá dispor a bancar sozinho o risco de recompra das ações no vencimento final, nem os efeitos de uma drástica diluição pela conversão futura das resgatáveis em ações de outra classe a valores baixos em relação ao patrimonial. Nesses casos, o Governo deve compartilhar na garantia de resgate, pois também é beneficiário da colocação inicial a valores maiores.

O novo proprietário terá o maior interesse em proporcionar o máximo lucro possível ao empreendimento, pois isto maximizará os seus lucros e favorecerá a conversão das ações preferenciais resgatáveis em ações comuns.

Ao serem criados mecanismos para a colocação de ações junto aos investidores, sejam eles compulsórios (fundos de pensão e seguradoras) ou não, estar-se-á assegurando um menor esforço financeiro por parte do privatizador. A sua menor necessidade de dinheiro representa maior saúde financeira, menor risco nos seus negócios atuais e naqueles que está adquirindo.

A existência de investidores compulsórios para o produto ação representa uma demanda real e uma ajuda efetiva no esforço de privatização, mas os gestores desses recursos farão todo o possível para evitar que sejam utilizados instrumentos inadequados.

É importante ressaltar que, ao utilizar ações preferenciais resgatáveis na captação de recursos para a privatização, será possível gerar ganhos sociais no desenvolvimento do mercado acionário, no mercado de crédito de longo prazo e na geração de tributos a serem recolhidos sobre os lucros futuros.

Finalmente, considerando que a inovação tecnológica é uma das soluções para o crescimento e desenvolvimento do Brasil, faz-se mister desenvolver e introduzir instrumentos inovadores, também e principalmente, na área financeira. Nesse sentido, a utilização das Ações Preferenciais Resgatáveis representa uma forma inédita e inovadora, tendo em vista as características atuais da nossa economia. Exatamente por se constituir numa inovação, alguns detalhes técnicos na utilização das Ações Preferenciais Resgatáveis devem ser melhorados e aprimorados, principalmente tendo em vista as condições vigentes de indexação e as peculiaridades de cada empresa a ser privatizada. $\square$ 